\title{
La Virgen María en la mirada de Fray Francisco de Osuna
}

\section{The Virgin Mary in the Gaze of Fray Francisco de Osuna}

\author{
José Luis López Reyes \\ Facultad de Teología San Isidoro de Sevilla \\ jlopezreyes@hotmail.com \\ ID ORCID 0000-0003-3645-3223
}

\begin{abstract}
Resumen: Probablemente estamos tratando al gran místico del Renacimiento español, por ese motivo es importante conocer su contexto histórico-teológico. La mariología de Osuna que es aún un campo por investigar, se podrá afrontar de forma más comprensible desde sus obras del Abecedario Espiritual, de donde este artículo pretende extraer su creer y pensar en la Madre Dios.
\end{abstract}

Palabras Clave: Mariología, franciscanismo, Madre de Dios

\begin{abstract}
We are probably dealing with the great mystic of the Spanish Renaissance, for that reason it is important to know his historical and theological context. Osuna's Mariology, which is still a field to be investigated, can be faced in a more understandable way from his works on the Spiritual Alphabet, from which this article tries to extract his belief and thinking about Mother God.
\end{abstract}

Key Words: Mariology, franciscanism, Mother of God

\section{INTRODUCCIÓN}

En todos los tiempos la mística en España ha contribuido de manera significativa al enriquecimiento espiritual de la Iglesia. Pero si tenemos que destacar un momento clave fue el siglo XVI y destacando a numerosos autores místicos y santos. Entre estos místicos ocupa un lugar Francisco de Osuna, que con su obra el Abecedario Espiritual llegó a ser conocido e iniciar una nueva forma de entender la mística y su práctica. Es difícil encontrar reseñas de forma explícita sobre la Virgen María porque en sus escritos predomina el método de oración del recogimiento muy encauzado a la contemplación de Cristo en la cruz. No obstante se pueden señalar algunas de las apreciaciones 
mariológicas que pueden desprenderse de la citada obra, profundizando así en aspectos teológicos relativos al misterio de María como son la virginidad, la maternidad o su inmaculada concepción, entre otras. Teniendo en cuenta especialmente la defensa del Dogma Inmaculista tan candente en la Orden a la que pertenecía el autor que este artículo trata. Se ha de advertir que el tema a tratar es prácticamente nuevo o ha tenido poca profundización entre los ya publicados sobre la obra de fray Francisco, puesto que ningún otro ha abordado los aspectos mariológicos y marianos de su vida y obra. Teniendo en cuenta esta doble apreciación, considerar su doctrina mariológica y la devoción hacia la Madre del Señor, siempre bajo el manto de la mística, así como por su contexto histórico y su contraste con la mariología actual, tiene cierta dificultad por la escasez de textos que Osuna nos ofrece.

Aun Así, la intención de este artículo solo pretende esbozar a María en la obra de Osuna para conocer cómo él y sus contemporáneos entendían la figura de la Virgen en relación a su Hijo, sus misterios, su implicación en la obra de la Salvación y la piedad popular que hacia ella siente el Pueblo de Dios. Conocer su visión en referencia a María es más fácil si conocemos su propia historia personal, la aportación de la orden franciscana en referencia a los debates mariológicos de su tiempo, el devenir histórico en el que vivió y su propio ascetismo, más ligado a la imagen de Jesús que a la de su Madre. Por este motivo y sin caer en ningún tipo de juicio anacrónico, se comparará la mariología desarrollada en el s. XVI con la de nuestros día.

Respecto al análisis del texto, del Abecedario espiritual, es necesario procurar ser lo más respetuoso posible por no leer más allá de lo que el autor realmente quiere decir. Por ejemplo, en pocas ocasiones se refiere a María en forma de texto extenso, más bien son referencias a ella simplemente como «la Virgen» en un contexto ya definido sobre otro tema, pero como buen franciscano tiene presente a la Madre del Señor. Por eso, estas consideraciones equivalen a no rechazar el «principio de cabeza vacía». Este principio se utiliza para no leer entre líneas lo que no se encuentre en el texto, y no determinar a priori lo que el texto quiere decir a expensas de lo que expresa efectivamente. Consiste en mantener la objetividad del que realiza el estudio en referencia al texto que es estudiado, para no introducir opiniones personales ajenas al propio autor, evitar cualquier precomprensión del mismo y dejar que sea el creador del texto el que nos hable por sí 
mismo. Actividad nada desdeñable para el propio investigador, que suele tener la tentación de atraer al texto estudiado a la teoría o tesis que quiere exponer. Sin embargo, este procedimiento no es una reproducción de los mismos signos del autor en el juicio del intérprete, más bien, es intentar exponer de forma objetiva lo que él quería decir, comparándolo con el tiempo en el que vivió y su prolongación hasta los estudios más recientes, lo cual, como se ha dicho anteriormente, nos lleva a considerar la mística que lo caracteriza en su contexto y prolongación en el tiempo hasta nuestros días. En este sentido, la interpretación de los textos no se limita a observar los signos escritos, es decir, su consideración meramente literal, sino que los coteja con estos otros para poder conseguir extraer realmente toda la esencia de la obra ${ }^{1}$. Teniendo en cuenta todo esto, la exposición de este artículo abordará la persona de Francisco de Osuna y la mística en el renacimiento español. Considerando las influencias en su pensamiento y espiritualidad, en relación al II Conde de Ureña, Francisco Quiñones, la Universidad de Alcalá, la «devotio moderna», la reforma villacreciana, la espiritualidad de Dionisio Aeropagita y la piedad popular hacia el Señor y la Virgen María, entre otros temas. De su mística es de obligado cumplimiento destacar el método orante del «Recogimiento», sus principios teológicos y espirituales, así como su propia experiencia, recordando el estudio y repercusión de su obra en el Tribunal de la Inquisición.

Entender el mundo en el que Osuna vivía nos muestra indicios de su propia mariología, no solo la del renacimiento, sino también su evolución hasta la contrarreforma, pasando por los protestantes y la doctrina de Trento. Habrá que tener en cuenta los ejes interpretativos más determinantes de este autor como son su condición franciscana y la mística, para una mejor comprensión en el análisis de su mariología. Se deberá tratar, por tato, la figura de María en la mística en general, su presencia en la Tradición de la Iglesia, concretándola especialmente en el siglo XVI y ofreciendo, finalmente una visión de su misterio cotejada con la mariología actual y a partir de la perspectiva histórico-salvífica marcada por el Concilio Vaticano II.

Analiza los aspectos mariológicos y marianos que pueden deducirse en la obra del Abecedario Espiritual de fray Francisco de Osuna, pasando por la oración en María, su condición de Sierva, la prefiguración

1 Cf., BERNARD LONERGAN, Método en Teología, 152-153 
de la Hija de Sión (que era recurrente en la mariología posconciliar) y aspectos doctrinales como su maternidad, virginidad, mediación y su inmaculada concepción. Las Apreciaciones mariológicas a propósito del Abecedario espiritual de fray Francisco de Osuna, en cuanto que se parte de esta obra paradigmática de la mística española para acercarnos al misterio de la Virgen Madre, tanto en el contexto místicomariano de la época, como a la luz de la mariología actual.

\section{CONTEXTUALIZANDO A FRANCISCO DE OSUNA}

Francisco nace en la Villa de Osuna en torno al año 1492. Se conoce su origen por la dedicatoria que le realiza al II Conde de Ureña que en aquel entonces era el señor de Osuna en el Tercer Abecedario Espiritual, que reza de la siguiente manera:

«Como yo desde niño me haya criado a vuestras migajas e mis antepasados hayan sido criados familiares de vuestra casa, pareciéndome cosa justa ofrecer mi primer fruto donde recibí el favor de mi tierna edad».

Pero no obstante es difícil poder conocer quién es este autor espiritual, porque incluso aun teniendo esta dedicatoria, son muchas las especulaciones que existen entre los expertos sobre su origen y la dedicación de su familia. Aunque lo más probable es que la realidad se adecúe a lo que escribiría en la anterior dedicatoria. La vida de Fray Francisco está rodeada de una gran capa de misterio, porque tampoco existen evidencias sobre su biografía más allá de lo que el mismo autor expresa o de las parcas menciones que los cronistas de su misma orden franciscana realizan sobre él.

Su familia pertenecía a los criados de confianza de un señor con una buena posición y una gran fortuna. Osuna, llegó a escribir en el «Norte de los Estados» la propuesta de la regla de vida de su sobrino «Villaseñor» ${ }^{2}$, por lo que se puede deducir que Francisco podría apellidarse «Villaseñor». También podría apellidarse «Osuna» aunque es poco probable, o haber cambiado su verdadero apellido (Villaseñor) por este, quizás por motivos de igualdad entre los demás hermanos

2 Este vive en un palacio y junto a su prometida reciben el título de «nobles novios». 
de la Orden, o porque realmente se apellidase así ${ }^{3}$. Lo que sí conocemos con seguridad es el periodo convulso en el que nace y vive, coincidiendo con la rendición de Granada, la conquista de América y, cuando contaba con unos doce años, la toma de Trípoli, en la cual acompañaría a su padre. Periodo en el que Sevilla se convertiría en el centro del mundo. En 1503 se emplazó en Sevilla la Casa de la Contratación y en 1526 las bodas del emperador Carlos V, encumbrándose así con una gran proyección internacional. Como se contempla el origen de Francisco es un misterio alentado aún más si cabe como la falta de información.

Las ideas que Osuna se plantea de reforma se complementaban perfectamente con el ideario de Francisco de Quiñones, el que fuese cardenal y ministro superior de los franciscanos, siendo él probablemente cuando era Vicario y gobernaba la provincia de Castilla (1512-1515), quien aceptara como postulante a Francisco. Quiñones protegió con especial atención a las monjas Concepcionistas, a las que dio sus primeras Constituciones (1513) y su primer Ceremonial (1524). De esta forma, la devoción a la Inmaculada Concepción persigue a Fray Francisco, aunque no se sabe con claridad en qué provincia franciscana ingresaría, si en la de Castilla o en la de Andalucía, no obstante, Pedro Álvarez mantiene que tomaría el hábito en el convento de Alcalá de Henares ${ }^{4}$. Así francisco ingresaría en la Orden Franciscana entre dos momentos importantes, el primero es cuando el Cardenal Cisneros recibe del Papa Alejandro VI la autorización oficial para su reforma en el año 1492, y en segundo lugar, antes que León X promulgara la Bula de Unión «Ite vos» en el año 1517.

Una vez finalizado el postulantado continuó con sus estudios de filosofía en el convento de Torrelaguna, pueblo natal de Cisneros, donde el arzobispo de Toledo había reunido una biblioteca especializada. Entre las preocupaciones de Cisneros en su papel como reformador fue la promoción cultural y espiritual del clero y del pueblo, haciendo una labor muy amplia en desarrollar y enseñar la doctrina

3 Cf., A. Y A. GARCÍA CARRAFA, Enciclopedia Heráldica y Genealogía HispanoAmericana, 66, Madrid, 1950, 94: «Los de este apellido (Osuna) son hijosdalgo originarios de las montañas de Burgos y fueron sus progenitores dos donceles que en tiempos del Rey Enrique II pasaron a Andalucía radicando en la villa de Osuna, en la provincia de Sevilla. Se apellidaban Pérez, pero al quedar establecidos en Osuna, tomaron el nombre de la villa por apellido». Cita a: Nobiliario. Libro Becerro de Castilla, M. f.75.

4 Cf., S. LÓPEZ SANTIDRIÁN, Tercer Abecedario Espiritual de Francisco de Osuna, 11. 
espiritual entre los siglos $\mathrm{XV}$ al $\mathrm{XVI}^{5}$. A la conclusión de la filosofía, iniciaría sus estudios de teología en Alcalá de Henares. Debido a que siguió las tres vías principales propias en el proceso educativo de su época, el tomismo, escotismo y nominalismo, ofrece pruebas para afirmar que estudió en la Universidad Complutense. Debido a esta formación, en el nominalismo seguirá a Gabriel Biel, que pertenecía a la cátedra de Alcalá. Biel era el último comentarista de Guillermo de Occam, considerado el mayor de los nominalistas ${ }^{6}$. A nivel de teología mística a se decantó por Gersón, puede que este sea el motivo por el que Osuna cita en varias ocasiones a lo largo de su obra a Occam. Pero siente además gran aprecio por Santo Tomás de Aquino o Ricardo de San Víctor. En opinión de Melquíades Andrés refiriéndose al nominalismo practicado en la universidad de Alcalá de Henares dirá: «Más que nominalismo habría que llamarlo espíritu de modernidad, de apertura, de progresismo, de búsqueda de la verdad. No se trata, por tanto, de nominalismo en sentido sistemático, sino de lo que se encubría bajo la expresión «Via modernorum» ${ }^{7}$. El nominalismo se había apoderado de la universidad alcalareña, que gracias través de Gabriel Biel conocieron el ideario de Guillermo de Occam, quien más allá de las reflexiones de Duns Escoto y en contraposición con San Buenaventura su idea de conocimiento es de índole exclusivamente científico. Pero aun teniendo en cuenta toda esta información, no se puede asegurar que Francisco se denominara nominalista, porque su formación le predisponía a ser un espíritu abierto, pero con inclinación a los teólogos de su propia Orden. Así es como el Cardenal Cisneros creó una Universidad realista y pastoral, con una teología enraizada en los Padres y las Escrituras, o lo que es lo mismo en las Sagradas Escrituras, la Tradición y el Magisterio de la Iglesia. Pero, aunque se presume que su formación académica fuese muy completa, prefirió realizar obras dirigidas al pueblo con escaso nivel académico. Esta tendencia no es exclusiva de Osuna, se puede ver también en fray Bernardino de Laredo o un poco posterior en fray Luis de Granada. Potenció los modos populares de expresión de la experiencia mística, en especial en sus obras escritas en romance; método contraindicado en el Renacimiento para alcanzar la fama.

5 Cf., D. DE PABLO MAROTO, Espiritualidad española del siglo XVI, Vol. I., Los Reyes Católicos, 47.

6 Cf. ETIENNE GILSON, El espíritu de la filosofía Medieval, 369-386

7 Cf., M. ANDRÉS MARTÍN, La teología española en el siglo XVI, n. II., 81. 
Paro afortunadamente se decantó por una espiritualidad sencilla, al alcance de los más humildes, dirigida a todos los públicos. Esta forma de escribir le supuso un gran esfuerzo, partiendo por enriquecer y elaborar un tipo de lenguaje propio menos docto para que fuese entendido por todos ${ }^{8}$. Es así como fue preparando el camino para la cumbre de la espiritualidad que podemos disfrutar en la actualidad"

Volviendo a su formación de corte escolástica, siendo especialista en la predicación y la mística, su código supremo se basa en el amor ${ }^{10}$. Hay que destacar que Osuna supo superar los recelos dentro de la Observancias a la Devotio Moderna con su tendencia hacia lo especulativo y analítico, convirtiéndose en puente para una nueva cultura espiritual. Allí donde la razón no comprende deben actuar los resortes afectivos de los sentimientos, sublimados por excelsa caridad.

A Francisco le influyen como es normal por el tiempo y lugar en el que vive la Devotio Moderna, que abarca todo el movimiento de renovación de la vida cristiana a partir de la segunda mitad del siglo $\mathrm{XIV}$, incluso puede extenderse hasta el siglo XV. La «Devotio» hace referencia a piedad, a una espiritualidad de tono afectivo, personal, íntimo, realista y práctica; pero no es en sí un sentimentalismo. Se podría definir como una persona que practica ciertos actos piadosos e intenta vivir virtuosamente. El adjetivo moderna, comprende el rechazo que los hombres devotos tienen a algunas teorías y prácticas religiosas difundidas por grandes místicos alemanes, a los iniciadores del Humanismo pre-renacentista. Aunque Groote y Radewijns, son los fundadores, también cabe destacar a autores como Ruusbroec, Juan Gerlac Peters, Tomás Kempis, Enrique Mande, Hadewijns, Gerardo Zerbolt de Zutphen o Juan Mombaer. La mayoría de origen flamenco, y que muchos de ellos fueron superados por los grandes místicos españoles del siglo XVI. Se puede intuir con gran facilidad que fray Francisco sería influenciado por estos autores, por sus obras,

8 Este estilo será menospreciado por algunos y alabado por muchos como el P. Crisógono de Jesús que diría, refiriéndose a los Abecedarios: «Libros admirables por el fondo y por la forma, casi resulta mengua para ellos calificarles de precursores de las obras de Teresa, o de Fray Juan de los Ángeles», Cf., P. CRISÓGONO DE JESÚS, Escuela mística carmelitana, 54.

9 Cf., S. LÓPEZ SANTIDRIÁN, Tercer Abecedario Espiritual de Francisco de Osuna, 13.

10 Cf., FRAY FRANCISCO DE OSUNA, III Abc., tr. 16: «Referir y sacar debes de toda cosa el amor». 
y también por el ambiente que él mismo pudo vivir en su estancia en los Países Bajos. Pero el que introduciría en España la metodización de la oración en línea más fiel con la Devotio Moderna flamenca sería García Jiménez de Cisneros (1456-1510), primo del famoso Cardenal Jiménez de Cisneros ${ }^{11}$.

Osuna es destinado a la Salceda, cerca de la localidad de Tendilla. Encontrándose en este lugar el centro de la reforma Villacreciana, convertido en un arsenal de la mística afectiva. Vivian en casas de recolección, que eran como baluartes de la reforma interior, trincheras pacificas en la lucha con la resistencia conventual. Sería Quiñones ${ }^{12}$ quien aprobase para España sus constituciones. La habitaban unas diecisiete personas por centro, dedicándose en silencio a la oración, el estudio y la penitencia. Sus Estatutos especificaban que: «Los frailes de estas casas singularmente resplandezcan en pobreza, penitencia, aspereza y oración» ${ }^{13}$. Aunque estas orientaciones variarían levemente en las demás Provincias de la Orden. En estas casas es donde se retiraban antes y después de la intensa predicación realizando lo que hoy entenderíamos como ejercicios espirituales para volver a su actividad. Francisco, cuando llega a la Salceda, intenta imitar a los que considera mejores en la práctica de la oración. Buscaría la sabiduría, el equilibrio y la paz de los ancianos cargados de mayor número de experiencias. En la Salceda se iniciaba el día con la meditación de la pasión de Cristo, acompañándole seguidamente la Eucaristía, donde asimilaban todo lo meditado y rezado ${ }^{14}$. Quizás por este estilo de vida monástica, el primer proyecto de Osuna era un libro en tres partes: la primera parte sobre la Pasión, la segunda sobre los ejercicios de la vida religiosa y la tercera sobre el Recogimiento u oración afectiva ${ }^{15}$.

No se puede dejar pasar la enorme influencia de Dionisio Areopagita en los místicos en general, y en especial en los del siglo XVI. No obstante, no se ha realizado un estudio amplio de esta gran influencia del Dionisio ${ }^{16}$ y más teniendo presente que entre los fran-

11 Cf., D. DE PABLO MAROTO, Espiritualidad de la Baja Edad Media, 310-333.

12 El mismo que recibió a fray Francisco como postulante.

13 Cf., L. CARRIÓN, Las casas de Recolección de la Provincia de la Inmaculada Concepción y estatutos porque se regian, 270.

14 Cf., S. LÓPEZ SANTIDRIÁN, Tercer Abecedario Espiritual de Francisco de Osuna, 15.

15 Ibíd., 256.

16 Cf., M. ANGÉLICA GONZÁleZ PÉREZ, La «teología Mística» de Dionisio Areopagita y su influjo en místicos españoles del siglo XVI, 291. También Cf., R. M. 
ciscanos de la corriente observante se desarrolló con fuerza gracias a los recolectorios ${ }^{17}$, en donde Osuna participó de forma activa junto con el hermano lego Bernardino de Laredo. En ambos franciscanos encontramos la presencia de los seguidores e intérpretes medievales de la teología mística de Dionisio, destacando a san Buenaventura, los Victorinos, Hugo de Balma y Juan Gersón, este último considerado por fray Francisco de Osuna como uno de los mejores intérpretes de Dionisio. Incluso se encuentran en la obra de Osuna menciones explicitas a Dionisio ${ }^{18}$. La vía negativa, que aparece en la obra del Tercer Abecedario Espiritual, expresa cómo por medio de esta vía se nos pide dejar la razón a un lado y nos invita a disfrutarlo sentimentalmente. Osuna en este punto se diferencia de Dionisio porque comprende que dentro de esta ecuación también deben encontrarse a los sentidos, incluso considerándolos como motivos de tentación. Quedando claro para ambos autores que solo por la vía negativa es posible el conocimiento de Dios. No pueden hacer una afirmación de la esencia; por ese motivo, Francisco se basa en Dionisio, cuando dice: «No es definible la divinidad, sino que más verdadera y llenamente el apartar muestra negando lo que no sea que no afirmado lo que sea» ${ }^{19}$.

Osuna desarrollará la oración de «el Recogimiento», siendo esta misma difícil de poder explicar, incluso el mismo autor no sabe cómo exponerlo, por eso, utilizará cuarenta apelativos distintos. Él mismo dice que mientras más términos se utilicen mejor se adecuará al que lo practique. El Recogimiento quiere expresarlo mediante diez efectos, desde los socio-antropológicos, las virtudes y los sentidos y la mística ${ }^{20}$. Las cuatro primeras prácticas son en un sentido preparatorio, afectando a la unidad interior de la persona que comenzará a ser verdadera cuando entre los recogidos hay concordia, abandono de las cosas del mundo, retraimiento a la soledad, finalizando con

PÉREZ GARCÍA, El argumento histórico acerca de la transmisión de la teología mística y la autoridad de Dionisio Areopagita en la España del siglo XVI, 26-47.

17 Conventos especialmente dedicados a la vida de oración, austeridad, silencio y recogimiento

18 Hasta siete menciones realizó de Dionisio en el III Abc Espiritual (Cf., páginas: 185-6, 473, 550, 595-6, 601, 602 Y 603), y en el IV Abc hasta nueve.

19 Cf., FRANCISCO DE OSUNA, Tercer Abecedario Espiritual, 589.

20 Cf., S. LÓPEZ SANTIDRIÁN, Tercer Abecedario Espiritual de Francisco de Osuna, 37. 
la mortificación de la sensualidad controlándola por la razón. Una vez que todo esto se alcanzó, se pasa a ejercicios que verifiquen la reducción en lo corporal y lo espiritual. En lo corporal se dirige a los sentidos y al cuerpo, teniendo especial cuidado a los ojos, porque son las puertas por donde se suele escapar el recogimiento. Esta reducción sensorial y corporal, traslada a otros ejercicios más interiores que afectan a la propia psicología. En segundo lugar, estarían aquellos que profundizan en una reducción mayor, que es donde finalmente se produce la unión con Dios, esto es, la divina claridad que se infunde en el alma. Francisco también orientará a otros ejercicios que acercan el hombre a Dios, sin tener una relación objetiva con el recogimiento, se refiere los que se unen a Dios por la vía activa apostólica, proponiendo a San Pablo. Otros ejercicios son aquellos que se dedican a la meditación de las vanidades temporales o lo que tienen que ejercitar aquellos que se colocan al servicio de los pobres con obras de misericordia ${ }^{21}$.

Finalmente, las obras de corte místico y romance de Osuna incluidas en el Index de libros prohibidos por la Inquisición, le produjo una muerte tipográfica, frenando en seco sus publicaciones. Ninguna de sus obras volvería a ser publicadas en España y ni en castellano, excepto una edición muy tardía del Tercer Abecedario, en el Madrid de 1638, aparecida en un contexto sociocultural muy diferente al de Osuna ${ }^{22}$.

\section{LA VIRGEN MARÍA EN EL PENSAMIENTO FRANCISCANO}

Cuando se afronta el tema de la Madre de Jesús, la teología franciscana se muestra empujada a hacerlo como consecuencia de su contemplación e investigación del misterio trinitario y especialmente cristológico. María no es considerada en sí misma sino en el plan de la salvación y en su vocación con el rol de Madre de Dios que se hizo humilde. Este es el misterio que fascina a Francisco de Asís y que está en la base de su propia vocación. El Dios inaccesible se hizo pobre y humilde por nosotros, siguió el camino de los pequeños, de la

21 Cf., VICENTE MUÑIZ RODRÍGUEZ, Experiencia de Dios y lenguaje en el Tercer Abecedario Espiritual de Francisco de Osuna, Lección Inaugural del curso académico 1986-1987, Universidad Pontificia de Salamanca, 20.

22 Cf., E., FOSALBA; Mª, JOSÉVEGA, Textos castigados, la censura literaria en el siglo de oro, 119-120. 
pobreza, de la obediencia al Padre.Y para ello eligió a una mujer que por su humildad y obediencia se adhirió al designio divino y, desde su pequeñez alcanzó una alta dignidad después de que Dios hizo al hombre. El principio fundamental de la mariologia franciscana parte de una regla cristológica: «Al exaltar a Cristo prefiero caer en exceso en la alabanza debida a él que en defecto, si por ignorancia no es posible evitarlos a ambos» ${ }^{23}$. De esta afirmación se deriva la mariológica: «Es bueno atribuir a María todo lo más sublime si esto no repugna a la autoridad de la Iglesia ni a la autoridad de la Escritura» ${ }^{24}$.

El famoso dicho «de Maria numquam satis» ${ }^{25}$ se redimensiona de esta manera para que todo discurso sobre la virgen esté siempre en armonía con la Escritura y la Tradición. Para ella, de hecho, que es la Madre de Dios, la más excelente debe ser considerada, ya que supera a todos en plenitud de gracia y belleza; pero toda excelencia no debe ir más allá de la revisión bíblica y teológica aceptada y aprobada por la iglesia ${ }^{26}$. Siguiendo la regla fundamental para interpretar el estudio de la Virgen María a la luz de la Escritura y la Tradición eclesial, es confirmado por el Magisterio en la siguiente afirmación:

«El santo Concilio enseña de propósito esta doctrina católica y amonesta a la vez a todos los hijos de la Iglesia que fomenten con generosidad el culto

23 Cf., Duns Scoto, J., Ordinatio III d. 13 q. 4

24 Ibíd., d. 3 q. 1. Un principio parecido encontramos en Buenaventura de Bagnoregio en su obra Opera Omnia III, 64, que dice así: «Nadie puede ser devoto de la Santísima Virgen durante demasiado tiempo para creer que es la verdad de las Escrituras y la fe cristiana».

25 Sobre esta fórmula se expresa Benedicto XVI diciendo:

"Cuando yo era un joven teólogo, antes e incluso durante las sesiones del Concilio, como sucedió y como le sucede todavía hoy a muchos, yo alimentaba algunas reservas sobre algunas fórmulas antiguas, como por ejemplo, la famosa de «María numquam satis» (de María nunca sabremos lo suficiente) está me parecía exagerada. También tenía dificultad para comprender el verdadero sentido de otra expresión famosa (tan repetida en la Iglesia desde los primeros siglos, cuando después de un memorable debate en el Concilio de Efesio del 431 se había proclamado a María Madre de Dios) que ve a María «victoriosa frente a todas las herejías». Hoy, en este periodo de confusión en la que todo tipo de desviaciones heréticas vienen a golpear a la puerta de la fe auténtica, hoy apenas he comprendido que no se trataba de una exageración de devotos, sino de verdades más que nunca válidas».

Cf., Cardenal Ratzinger, Entrevistas sobre la Fe, Vittorio Messori - Fayard, 1985.

26 Cf., Cecchin, E. M., Maria Signora Santa e Inmacolata nel penssiero francescano, per una Storia del contributo francescano alla mariologia, Pontificia Academia Mariana INTERNATIONALIS, 1-2. 
a la Santísima Virgen, particularmente el litúrgico; que estimen en mucho las prácticas y los ejercicios de piedad hacia ella recomendados por el Magisterio en el curso de los siglos y que observen escrupulosamente cuanto en los tiempos pasados fue decretado acerca del culto a las imágenes de Cristo, de la Santísima Virgen y de los santos. Y exhorta encarecidamente a los teólogos y a los predicadores de la palabra divina a que se abstengan con cuidado tanto de toda falsa exageración cuanto de una excesiva mezquindad de alma al tratar de la singular dignidad de la Madre de Dios. Cultivando el estudio de la Sagrada Escritura, de los Santos Padres y Doctores y de las liturgias de la Iglesia bajo la dirección del Magisterio, expliquen rectamente los oficios y los privilegios de la Santísima Virgen, que siempre tienen por fin a Cristo, origen de toda verdad, santidad y piedad $»^{27}$.

Que Francisco de Osuna sea franciscano lleva a considerar las líneas fundamentales de la mariología desde la teología franciscana como ya reseñamos antes. Por ese motivo, al hablar de «mariología franciscana», nos referimos a la espiritualidad y teología orientada en sentido mariano e históricamente unida con la piedad y la contemplación mariana comenzada por Francisco de Asís y estructurada cristocéntricamente ${ }^{28}$. La mariología franciscana se distingue sobre todo por el reconocimiento de la Inmaculada Concepción de María, pero la defensa de este Dogma fue el punto culmen en el pensamiento franciscano medieval, donde también podemos encontrar numerosas relaciones de María con el misterio de la Encarnación de Dios, que se sigue desarrollando hasta la actualidad ${ }^{29}$.

San Francisco de Asís, desde sus inicios, se unió a María en la capilla de María de la Porciúncula, donde se originó la Orden franciscana. Francisco, tiene, por tanto, la referencia la maternidad divina, y la relación de esta con la Trinidad, y de un modo especial con el Espíritu Santo. Es así, que Francisco contempla a María al servicio de la redención y glorificación de la Trinidad, servicio que sigue ejerciendo aun en el cielo, como súplica por todos nosotros. Ella, fruto prematuro de la obra del Redentor, ejerció su actividad en la tierra cooperando con Él y dejándonos ejemplos de humildad y esperanza,

27 Cf., Concilio Vaticano II, Lumen Gentium, 67.

28 Cf., J. A. MERINOY F. MARTÍNEZ FRESNEDA, Manual de teología franciscana, 251; También Cf., STEFANO M. CEECHIN, Maria Signora Santa e Inmacolata nel penssiero francescano, 1-5.

29 Ibíd., 252; y también en Cf., STEFANO M. CEECHIN, Maria Signora Santa e Inmacolata nel penssiero francescano, 17. 
que nos disponen a acoger con fe los frutos de la redención ${ }^{30}$. La maternidad divina es el elemento vertebrador de la fe en María de Francisco ${ }^{31}$.

Francisco defiende el dogma cristológico y mariano de la encarnación insistiendo en la pobreza de María en el nacimiento de Jesús en Belén, mezclando elementos derivados de la devoción popular con elementos de los evangelios apócrifos ${ }^{32}$. Esta plenitud de la gracia de la Virgen que Dios le otorgó en grado sumo, ha sido querida por Dios porque la predestinó a ser el templo viviente de su Hijo que ella acogería con su consentimiento ${ }^{33}$. Estas gracias que María recibió de Dios la dispusieron para donar su fiat y capacitarla para vivir la relación especial con la Trinidad. Así, el título «esposa del Espíritu Santo» fue expresado por primera vez en la historia por Francisco, aunque en la literatura griega y latina fue expresado con términos similares $^{34}$. «Esposa del Espíritu Santo» significa que María, fortalecida con los dones divinos de la gracia, ha respondido a la llamada y ha dado su consentimiento libre a la acción del Espíritu Santo, concibiendo primero en el corazón y después en su seno. Por ese motivo, María se convierte en la Theotokos en el sentido pleno de la palabra.

Se entiende tras las afirmaciones de san Francisco de Asís sobre la santidad de María que pasara a darle el título de «Concebida sin pecado». Este paso en el pensamiento de Francisco lo sugiere tan sólo una expresión suya referida a la Virgen: «no ha nacido en el mundo entre las mujeres ninguna semejante a ti» ${ }^{35}$. Aunque en la época de Francisco la piedad popular y la reflexión de la teología se anclaban en la glorificación de María por ser la obra primordial de la gracia misericordiosa de Dios, por la que ella fue Madre e

\footnotetext{
30 Ibíd., 253.

31 Cf., STEFANO M. CEECHIN, Maria Signora Santa e Inmacolata nel penssiero francescano, 47-51. También Cf., Segunda carta a todos los fieles (2 Cta. De san Francisco, 4ss).

32 Cf., J. A. MERINOY F. MARTÍNEZ FRESNEDA, Manual de teología franciscana, 256

33 Cf., G. CALVO MORALEJO, María nell'esperienza mistica, en E. BOAGA E L. GAMBERO, Storia della mariología», dal modello letterario europeo al modello manualistico, vol. 2, 422; También Cf., STEFANO M. CEECHIN, Maria Signora Santa e Inmacolata nel penssiero francescano, 14-17.

34 Cf., I. PYFFEROEN-O.VAN ASSELDONK, María Santissima e lo Spirito Santo in San Francesco d'Assisi, 446-474

35 Cf., OFP: Antífona Completas.
} 
Inmaculada, siendo el fruto perfectísimo de la divina misericordia ${ }^{36}$. Francisco predica a «María mediadora», esta afirmación la realiza en el contexto de sierva especialísima y singular de la obra del único Mediador $^{37}$. Francisco ve en María el «tipo» de creyente, la madre de los fieles y la fe de María y de los demás creyentes que se hace actual por obra del Espíritu Santo ${ }^{38}$. Siguiendo esta línea se observa una metodología franciscana que comienza en su propio fundador. Francisco de Asís había entendido bien que la verdadera teología «proviene de la fe y tiene la intención de llevar a la fe» ${ }^{39}$. Por tanto, la verdadera sabiduría radica en seguir el camino de la verdad y el camino de la belleza donde la ciencia ilumina lo que cree la fe, en un itinerario mariológico y mariano al mismo tiempo ${ }^{40}$. Cabe señalar que el pensamiento mariano franciscano encuentra su fundamento en el «primado de Cristo», quien, como decía Carlo Balic, se ha convertido en la base de toda afirmación sobre María ${ }^{41}$. La creación depende de la Encarnación, como dice Buenaventura, todo fue creado para Cristo. Sin el Verbo Encarnado, de hecho, nada se habría creado en base a él, por eso, es el verdadero Rey, es decir, la piedra fundamental en la que todo se construye como un templo santo. La creación, en la humanidad del Verbo encarnado encuentra su plenitud, y se eleva de su condición de pecado y distanciamiento de Dios a la capacidad de adorar a la Trinidad en el verdadero culto glorificador. Todo, está ordenado y subordinado al Cristo glorificador, que en la condición de adorado da gloria infinita a Dios, y en la condición de adorado se glorifica infinitamente a sí mismo la criatura ${ }^{42}$. Y por eso, la Madre-

36 Sobre la Inmaculada Concepción en Francisco, Cf., P.-D. FEHLNER, Saint Francis and Mary Inmacolate, 502-519.

37 Cf., S. LÓPEZ, María en la comunicación salvadora de Dios trino en Jesucristo según s. Francisco, 339-370

38 Cf., J. A. MERINOY F. MARTÍNEZ FRESNEDA, Manual de teología franciscana, 263

39 Cf., JuAn Pablo II, Pastores Dabo Vobis, 53

40 Cf., CECCHIN, E. M., Maria Signora Santa e Inmacolata nel penssiero francescano, per una Storia del contributo francescano alla mariologia, PONTIFICIA ACADEMIA MARIANA INTERNATIONALIS, 6.

${ }^{41}$ Cf., BALIC, C., Predestination de la trés sainte Vierge dans la doctrine de Jean Duns Scot, la France franciscaine, 19, 1936, 114-158.

42 Cf., CECCHIN, E. M., Maria Signora Santa e Inmacolata nel penssiero francescano, per una Storia del contributo francescano alla mariologia, PONTIFICIA ACADEMIA MARIANA INTERNATIONALIS, 6. 
Virgen, predestinada «ab aeterno» a generar el Verbo según la carne, se concibe como causa contribuyente de la creación universal. Cristo y María son los primogénitos de la creación, para ellos todo fue creado, convirtiéndose en causa ejemplar y final de todo, de los ángeles, de los hombres y del universo entero. La Madre y el niño están tan íntimamente unidos que el primado de Cristo está en estrecha correlación con el de María ${ }^{43}$.

La Iglesia nace entonces con la Encarnación del Verbo. En ese momento ya está presente la Cabeza, es decir, en elVerbo Encarnado y sus miembros representados por la misma María, la hija de Sión, la primera creyente, la madre espiritual de la Iglesia ${ }^{44}$. Es en esta visión en la que se mueven los autores franciscanos vinculados al principio escotista de la predestinación absoluta de Cristo, por lo que Escoto prefirió, si no podía evitarse, caer en el fuego de la alabanza antes que en el minimalismo. Por lo que también en Mariología Escoto forma parte del principio, que luego será considerado el «franciscalis theologiae marialis norma». Por tanto, la norma de la investigación mariológica en general, como la franciscana en particular, tiene como principio la fidelidad al dato bíblico y a la tradición eclesial. La exageración está limitada precisamente por esta fidelidad, tanto que de ella se produce no una mariología «de privilegios» sino de verdad. Donde, reconociendo y partiendo de las verdades de fe de la Iglesia y siguiendo la vía pulcritudinis, se cubre la suprema dignidad de María, que comparte solo con Dios Padre ${ }^{45}$.

Desde la Edad Media se suele afirmar que la Virgen María había sido preservada del pecado original en atención a su dignidad de Madre de Dios, que esta dignidad era de alguna forma infinita, sin pecado, ni imperfección durante toda su vida, así había gozado de determinadas gracias carismáticas como la ciencia infusa y la visión beatífica en algunos momentos de su vida. Estos rasgos venían

43 «Similis Christo Maria in predestinatione. Similis, inquam, in praedestinatione, quoniam Christus predestinatus est non ut Deus, sed ut huomo Filius Mariae, ergo una cum Christo praedestinata est Maria». Cf., De Brindis, L., Sermo V in Concepcione Inmaculata, Mariale, Padua, 1928, 454.

44 «María, llevando al Hijo de Dios en su seno, había encerrado a todo el Cristo místico, que es la cabeza y el cuerpo de los elegidos, que es la Iglesia». Cf., Bernardino, El glorioso nombre de María, Opera Omnia VI, 93.

45 Cf., Bernardino, Quadragesimale de Christiana religione, Sermo 61, Opera Omnia II, 376. 
a configurar su imagen teológica ${ }^{46}$. Por eso, esta época destaca como la más importante y gloriosa de la mariología española y, por tanto, la más conocida ${ }^{47}$. Se estudiaron temas claves en la mariología por parte de los teólogos de la época clásica como la predestinación de María y su pertenencia al orden hipostático ${ }^{48}$, la maternidad divina en todas sus dimensiones: como gracia, raíz, virginidad y fuente de gracia, como dignidad singular... la virginidad perpetua, la asunción a los cielos ${ }^{49}$, la realeza, la inmaculada concepción con la problemática del débito, la gracia, la mediación y la santidad de María. Pero hay que destacar especialmente su inmaculada concepción, la muerte de María, la maternidad divina como gracia singular, que selló y santificó a María y la mediación de María ${ }^{50}$. Aunque se ha prestado poco interés a la mariología española de la primera mitad del s. XVI. No existen grandes figuras teológicas, pero es verdad, que destacan algunos teólogos que vivieron en la conjunción de las dos mitades del siglo, por ejemplo, Bartolomé de Torres ${ }^{51}$.

Por el otro extremo encontramos que, contra una malentendida forma de comprender la figura de María, Erasmo de Rotterdam exigirá una vuelta a los textos bíblicos originales, el estudio de la filología para la correcta interpretación de las Escrituras y una purificación del culto mariano. Erasmo también tradujo «gratiosa por gratia plena», pretendiendo excluir de todo mérito a María en referencia a la gracia de la maternidad divina ${ }^{52}$. Algunos llegan a considerar a Erasmo un enemigo del culto a María, porque critica la devoción popular y se opone a ciertas afirmaciones poco acertadas de los escritores devotos. Él mismo se defiende de estas acusaciones diciendo que ataca únicamente las exageraciones y desviaciones de la devoción mariana,

46 Cf., ENRIQUE LLAMAS, Mística y Mariología. Piedad mariana y misticismo en el siglo XVI, en ESTUDIOS MARIANOS, n45, 1980, 28

47 Cf., E. LLAMAS, Mariología, o. c., 1423.

48 Ibíd., Predestinación de María y pertenencia al orden hipostático según los mariólogos españoles de la época clásica, en EST MAR, 25, 1963, 101-148.

49 Cf., SIMEÓN DE LA SAGRADA FAMILIA-JOAQUÍN DE LA SAGRADA FAMILIA, La escuela de Salamanca y la Asunción de María, Monte CARmelo, 1947, 125-163.

50 Cf., G. M. ROSCHINI, La Madre de Dios, Tomo 1, 148-151.

51 Cf., E. LLAMAS, Bartolomé de Torres, entre el tomismo y el escotismo en el s. XVI, en HOMO MUNDUS, acta V Congressus Scotistici Internationalis, Roma, 1984, 501-517.

52 Cf., ERASMO, Novum Testamentum, en OPERA OMNIA, VI, 223-226. 
no la devoción en $\mathrm{s}^{153}$. En esta línea, pero mucho más extremo se propagaría en el siglo XVI diferentes herejías y cismas que sacudieron a la Iglesia Católica, a lo que esta respondió con el Concilio de Trento para dar una respuesta a los vaivenes teológicos del momento, ofreciendo una doctrina sana a la que el pueblo de Dios pudiese atenerse.

\section{MARÍA EN EL ABECEDARIO ESPIRITUAL DE FRAY FRANCISCO DE OSUNA. PERSPECTIVAS GENERALES}

Si solo estudiáramos a la Virgen María en el III Abecedario Espiritual de fray Francisco de Osuna poco ocuparía dicho estudio, pues solo menciona a María aproximadamente 101 veces en toda esta obra. Que, contando con la extensión de esta, se podría calificar como escasas las apariciones de la Madre del Señor. Es incluso más llamativa esta ausencia de la imagen de la Virgen María, teniendo en cuenta que en la época en la que es escrita esta obra, había una gran controversia sobre el culto mariano como tratamos anteriormente. Por ese motivo, es difícil poder extraer conclusiones inamovibles sobre la propia devoción de Osuna o tan solo su pensamiento respecto a la mariología. Aunque se pueden extraer diferentes «esquirlas» en la fe que este franciscano tiene a María, cuál es su pensamiento mariano someramente y qué papel juega la figura de la Madre de Dios en su obra y en la historia de la salvación.

La Iglesia tiene como ejemplo de oración a María, porque conforme a su piedad personal y a su modo de relacionarse con Dios, se modela también el espíritu de nuestra oración. Se pueden encontrar un ejemplo claro al seguir los testimonios bíblicos, donde se encuentra la oración en forma de himno que se le atribuye a María, el Magníficat ${ }^{54}$. Para nosotros es inimaginable la profundidad de la oración de María, por eso, en su respuesta al ángel: «hágase en mí según tu palabra» ${ }^{55}$, indica ya la primera actitud de la oración eclesial: la dócil sumisión a la voluntad de Dios, pero vivida en una familiaridad filial y maternal. La oración es, junto con la fe, un sacrificio en la ofrenda de coparticipación en la misión de su Hijo. Es así como la oración de María se muestra como una anticipación de la oración

\footnotetext{
53 Ibíd., 239.

54 Lc1, 46-55.

55 Lc1, 38.
} 
hecha al pie de la cruz, convirtiéndose en una oración de coofrecimiento junto con su Hijo, en la hora suprema del Gólgota ${ }^{56}$. Así como, el Ave María es la oración bíblica que constituye el elemento elogioso del Ángelus, utilizado en actos de alabanza y bendición dirigidas a la Madre y al Hijo, a la «llena de gracia» y al «fruto bendito» del útero virginal. Es la oración eclesial que representa el elemento de súplica y solicita la intercesión de María ${ }^{57}$. Osuna referente a la oración de María y la necesidad de su devoción para obtener la gracia de la eterna salvación, parte de tres principios fundamentales: su condición de Madre de Dios, su condición de Madre de los hombres y su condición de Mediadora entre Dios y los hombres ${ }^{58}$. Basándose en lo anterior dirá Osuna:

«Las religiones principalmente fueron instituidas para orar, y aunque la vida activa en ellas sea también necesaria, la contemplación había de ser más seguida. Donde San Bernardo dice: De haber bien elegido, es María loada; porque ciertamente aquella vida de todo en todo en cuanto en nos es habíamos de elegir, y la vida activa, si nos es mandada de nuestro mayor, hémosla de sufrir. De las cosas ya dichas concluye cuán de culpar sean los religiosos indevotos, ca vinieron a la religión, que es casa de oración, a orar» ${ }^{59}$.

Quizás por ser una oración tan común, fray Francisco tiene al Ave María como invocación a la Madre del Señor que es protectora contra el maligno. Osuna en su intuición no va mal encaminado, ya que en el Génesis, Eva recibe de Dios la promesa de una descendencia que será vencedora del maligno y la de ser madre de todos los vivientes. Es así, como María es la que después de la larga espera de la promesa, se cumple el plazo y se inaugura el nuevo plan de salvación ${ }^{60}$. Aunque se tiene que reconocer que no es algo novedoso,

56 Cf., E. LODI, Oración mariana, en S. DE FIORES, S. MEO ELISEO TOURÓN, Nuevo diccionario de Mariología, 1488-1490.

57 Cf., CURIA GENERALIS OSM, Angelus Domini, Celebrazione dell'annuncio a Maria, Roma, 1981, 10.

58 Cf., GABRIEL Ma ROSCHINI, La Madre de Dios Según la fe y la Teología, Tomo II, 540.

59 Cf., S. LÓPEZ SANTIDRIÁN, Tercer Abecedario Espiritual de Francisco de Osuna, 386. En el Tratado Cuatroceno, Habla de cómo hemos de corregir nuestra ánima, diciendo: «Por amor y sin enojo corrige siempre tu ánima». Capítulo IV, En confirmación que debemos orar siempre. Hace referencia a la Virgen María, no a la hermana de Lázaro

60 Cf., CONCILIOVATICANO II, Lumen Gentium, 55. 
pues en esta misma línea se le reconoció tempranamente a María un papel de intercesión ante el Señor. San Ireneo la llama «Advocata Evae», a lo que es lo mismo, la considera capaz de interceder como la progenitora del género humano ${ }^{61}$. La oración mariana tiene sentido porque es ante todo una confesión de las bases de nuestra fe, en la encarnación (Madre de Dios) y en la redención (nueva Eva al pie de la Cruz). Además, la oración mariana es un himno de alabanza a la magnificencia divina, porque en María hace transparente la fidelidad, la sabiduría y la ternura del Padre. También la oración exalta a la mujer cuya vida fue no solo una ayuda instrumental para el único Mediador, sino también una continua renovación del fiat redentor, puesto al servicio de la salvación de los hombres. Fray Francisco se manifiesta en referente a lo anterior de la siguiente manera:

«Debes mucho de temer, cuando determinas tornar atrás, que no sea causa de ello algún pecado oculto que haya en ti, o de proprio amor o de otra cosa ajena de Dios, porque no es pequeño azote que viene sobre ti el determinar de té apartar de la oración por darte a no sé qué obrillas de la vida activa, que, comparadas a las que Santa María hacía, son poco más que basura; así que cuando determinares de té apartar del Recogimiento, debes comenzar a hacer penitencia de algún pecado si hay en ti, según aquello de Job $(11,14-18) »^{62}$.

Cuando Osuna se expresa sobre la mediación de María tendrá en cuenta que por lo general, en los textos patrísticos cuantos más antiguos son, más consideran a María como medianera. Puesto que piensan principalmente en su cooperación en la realización de la misma obra de redención de Cristo, especialmente con su «sí» de la anunciación ${ }^{63}$. Más recientemente fue necesario el esfuerzo de clarificación del Concilio Vaticano II para explicar que toda mediación subordinada, «se entiende de manera que en nada menoscabe ni le añada nada a la dignidad y eficacia de Cristo único mediador» ${ }^{64}$. La solución se

61 Cf., L. GAMBERO, «Culto» en S. DE FIORES, S. MEO ELISEO TOURÓN, Nuevo Diccionario de Mariología, 538-539.

62 Cf., Cf. S. LÓPEZ SANTIDRIÁN, Tercer Abecedario Espiritual de Francisco de Osuna, 594.

63 Cf., G. M. ROSCHINI, La Madre de Dios, Vol. II, 567-568.

64 Cf., CONCILIOVATICANO II, Lumen Gentium, 62; Cf., GABRIEL M ${ }^{a}$ ROSCHINI, La Madre de Dios, Vol. II, 492-502; Cf., MIGUEL BRUGAROLAS BRUFAU, Jesucristo, Único Mediador: fundamento para una mariología de la mediación, en revista ESTUDIOS MARIANOS, Vol. LXXXIV, 2018, 111-112. 
consiguió recurriendo al concepto técnico de participación ${ }^{65}$. Osuna en esta cuestión se manifestaba de la siguiente manera:

«Nuestro pan de cada día, que es tu amado Hijo, nuestro Señor Jesucristo, dánoslo hoy en memoria y en inteligencia y en reverencia del amor que nos tuvo, y de las cosas que por nosotros dijo e hizo y sufrió.Y perdónanos nuestras deudas por tu inefable misericordia y por la virtud de la pasión de tu amado Hijo, y por los merecimientos e intercesión de la beatísimaVirgen María y de todos los escogidos, así como nosotros perdonamos a nuestros deudores; y lo que enteramente no perdonamos, haz tú, Señor, que plenariamente lo perdonemos, para que verdaderamente amemos por amor de ti a nuestros enemigos y debidamente roguemos acerca de ti por ellos, no dando a ninguno mal por mal, y que estudiemos aprovechar a todos en ti. Y no nos traigas en tentación oculta o manifiesta o subitánea, ni que dure un momento; mas líbranos del mal presente, pasado y por venir. Amén» ${ }^{66}$.

Cornelio Jansenio (entre otros herejes) se opondrá a la doctrina de la mediación mariana en el orden de la gracia o dirigirse a Dios poniendo como intercesora a María, práctica que ya se realizaba en la piedad popular. Por este motivo, el jansenismo combatió sin descanso la incipiente doctrina de la mediación universal de María ${ }^{67}$. Pero el Concilio de Trento al oponerse a las tesis protestantes se posiciona a favor de la mediación de María, al igual que fray Francisco como se puede comprobar por sus obras. Sin embargo, incluso en nuestros días la cuestión de la mediación de María fue muy discutida y profundizada por los padres conciliares del Concilio Vaticano II,

65 La participación tiene dos notas fundamentales: la primera es que toda perfección que hay en el ser que participa procede del ser que es fuente de la que se participa.Y en segundo lugar, la participación del que participa no es superior del que se participa. Cf., CÁNDIDO POZO, María nueva Eva, 367-369.

66 Cf., S. LÓPEZ SANTIDRIÁN, Tercer Abecedario Espiritual de Francisco de Osuna, 361. Terciodécimo Tratado, nos enseña cómo nos debamos haber en el sueño, diciendo: oración antes del sueño ten, y después torna presto. Capítulo II, De una declaración que hizo san Francisco sobre el «Pater noster». Hay muchos más ejemplos donde Osuna referencia a la mediación, como ejemplo en su VI Abecedario Espiritual: «Como la Virgen María a manera de María hermana de Moisés guardó el pandero de la fe debajo del manto hasta haber hallado el mar de la pasión y comenzó a bailar en la resurrección. Como la Virgen María es nuestra medianera para componer paz entre nosotros y Dios». Cf., FRAY FRANCISCO DE OSUNA, VI Abecedario Espiritual, edición facsímil, 22.

67 Cf., A. M. CALERO, María en el misterio de Cristo y de la Iglesia, Colección ESTUDIOS TEOLÓGICOS, 1, 42. 
incluso sería siendo el capítuloVIII de la Lumen Gentium ${ }^{68}$ dedicado a María, el más controvertido. Pero el Concilio no solo no despejó las posibles dudas o propuestas, más bien no entró en definición alguna, aunque sí señaló los elementos esenciales. Por ejemplo, en el capítulo VIII de la Lumen Gentium se omiten conscientemente los títulos de corredentora y mediadora, y los términos respectivos de mediación y corredención ${ }^{69}$.

Fray Francisco tiene una especial inclinación hacia laVirgen es su disposición de madre. María es así presentada como una madre en la que poder descansar, en la que encontramos consuelo y sosiego; es quizás por eso, que en el paso del tiempo se ha seguido manteniendo esta imagen de María. Si es Madre de Jesús por la «Communicatio idiomatum», es Madre de Dios, y si es Madre de Dios, el género humano por la adopción filial, obtenemos la maternidad de María, así es la Madre de Dios y madre de la humanidad. Osuna en su meditación expresa:

«Si permitiéndolo la justicia de Dios, y mereciéndolo el poco amor que le tienes, no rehúye luego tu voluntad, ni se aparta del pecado que se le representa, paréceme que debes ponerte a razón contigo mismo y decir: ... Si bien miras en ello, ¿con qué cara osarás volverte a Dios ni parecer delante su bendita Madre, si una vez te apartas de ellos?, ¿no sabes que el demonio, deseoso de tu perdición, está esperando el fin de tu daño?, ¿qué es de la pasión de Jesucristo?, ¿qué es de la compañía de los siervos de Dios?,

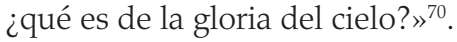

Fray Francisco utiliza muchas otras formulaciones para hacer referencia a la maternidad divina de Jesús y de la Iglesia, como por ejemplo la siguiente:

68 Cf., CONCILIO VATICANO II, Lumen Gentium, cap. VIII; Cf., JUAN PABLO II, Redemptoris Mater, cap. 3.

69 Solo una vez se encuentra el término de mediadora, pero junto con los de abogada, auxiliadora, socorredora, con el significado que les dieron los Padres de la Iglesia, y no en la forma de entenderlo de los teólogos de estos últimos años. Está acción se realizó con la intención de no inducir a equívocos o errores. Cf., S. MEO, «Mediadora» en S. DE FIORES, S. MEO ELISEO TOURÓN, Nuevo Diccionario de Mariología, 1305-1306.

70 Cf., S. LÓPEZ SANTIDRIÁN, Tercer Abecedario Espiritual de Francisco de Osuna, 538. 
«Nuestro Señor aceptando aquella llaga salió gotas de sangre que manaban hasta la tierra acordando el dolor que la virgen su Madre tenía de padecer viendo llagar el costado de su Hijo difunto...Fue llaga porque el mismo Cristo antes de la pasión pensando en ella la sintió bien, y nuestra Señora al tiempo de la pasión también la sintió. Porque como ella estaba al pie de la cruz y vielle que su Hijo inclino la cabeza hacia ella y suspiró. No pudo más sostenerse en pie sino cayó junto a la cruz» ${ }^{71}$.

Francisco muestra a María en colación a su maternidad como Virgen, siguiendo la Tradición de la Iglesia, cuando dice:

«Quien más perfectamente tuvo la experiencia de ello fue la Virgen sin mancilla, cuando todo se evacuó y ofreció su corazón muy limpio, vacío de toda operación distractiva, para que en aquella descensión del Espíritu Santo sobre ella la virtud de Dios causase en su corazón con tinieblas divinales, y puesta a la sombra de ellas, concibiese al hijo de Dios» ${ }^{72}$.

De esta forma, en María virgen-madre se realiza según el plan salvífico de Dios una doble acción, la demostración de la soberanía de Dios y la vocación a la colaboración del hombre en el orden de la aceptación ${ }^{73}$.

En relación al Dogma de la Inmaculada Concepción, cuyo significado es que María fue inmune de pecado original (fórmula que definió infaliblemente Pio $\mathrm{IX}^{74}$ ), hay que reconocer el mérito de san Agustín, que aunque tuviera una postura un poco enigmática a este respecto, de haber planteado correctamente el tema de la inmaculada concepción de María. La encuadra en los datos que se poseen acerca del pecado original y especialmente en la soteriología. A partir de entonces, la prerrogativa mariana sólo podrá presentarse como un caso de redención obrada por Cristo ${ }^{75}$. Osuna no es indiferente

71 Cf., FRAY FRANCISCO DE OSUNA, VI Abecedario Espiritual, edición facsímil, 66. Muchos son los autores que mantienen la imagen de María al pie de la cruz como análoga a la imagen de la Iglesia al pie de la cruz.

72 Cf. S. LÓPEZ SANTIDRIÁN, Tercer Abecedario Espiritual de Francisco de Osuna, 174.

73 Cf., S. DE FIORES, «Virgen» en S. MEO ELISEO TOURÓN, Nuevo Diccionario de Mariología, 2030-2031.

74 Cf., CÁNDIDO POZO, María en la obra de la salvación, 296; Cf., STEFANO M. CECCHIN, Maria, Signora Santa e Inmacolata nel penssiero francescano, 327-328.

75 Cf., STEFANO DE FIORES, María sintesis de valores, 226. 
a esta cuestión que en su época comenzaba a estar en boga, por ese motivo escribirá:

«El remedio de todas estas cosas es dejar llegar la razón, y que luego comience a detestar y tener en abominación toda deshonestidad, mirando hombre que es amigo y siervo leal de la Virgen sin mancilla, Señora de todos los castos» ${ }^{76}$

Desde la escuela franciscana a la cual pertenece fray Francisco, mantenía que, si María había sido predestinada en modo absoluto como Madre de Dios anteriormente a la previsión del pecado original, no tendría que estar sometida de ninguna manera al pecado original. No solo no contrajo el pecado original, sino que ni siquiera el «débito» ${ }^{77}$ de contraerlo, en el sentido en que, desde el momento de su concepción, María estaba libre también de la ley universal de contraer pecado $^{78}$.

\section{CONCLUSIÓN}

Si de alguna forma se puede entender el sentir de fray Francisco a la Virgen María y a su divino Hijo sería como él mismo dice:

«Éste es el fíat de la Virgen, en que consiste la suma perfección del amor, cuyo fin es conformarnos por entero en todas las cosas adversas y prósperas al amado con entero corazón; no solamente sufriendo en paciencia cualquier cosa que se ofreciere con entera conformidad, sino rogar nosotros que sea hecho lo que antes no queríamos; de manera que el amor no menos se deleita en lo que Dios hace, al revés de lo que Él demanda, que se deleitará si se cumpliera lo que primero quería» ${ }^{79}$.

En este párrafo se condensa lo poco o mucho escrito por este franciscano que en una época convulsa se convirtió en uno de los

76 Cf., S. LÓPEZ SANTIDRIÁN, Tercer Abecedario Espiritual de Francisco de Osuna, 538.

77 Débito referido como la necesidad directa o indirecta, próxima o remota. Cf., STEFANO M. CECCHIN, Maria, Signora Santa e Inmacolata nel penssiero francescano, 338-253.

78 Cf., J. A. MERINOY F. MARTÍNEZ FRESNADA, Manual de teología franciscana, 318; Cf., CÁNDIDO POZO, María en la obra de la salvación, 313.

79 Cf., S. LÓPEZ SANTIDRIÁN, Tercer Abecedario Espiritual de Francisco de Osuna, 443. 
místicos más reconocidos del siglo de oro español. La comprensión de la Madre del Señor como mujer creyente, de fe, entregada sin objeción a la voluntad de Dios y a su divino Hijo, conlleva una relación al nivel más sobrenatural entre la Madre de Dios y la Trinidad, atrayendo estos dones y gracias al propio ser humano. Fray Francisco de Osuna quiere mostrar que de las gracias de María, Nueva Eva, se encuentra participando toda la humanidad. El Verbo eterno al hacerse carne, consigue para el género humano la filiación divina y la redención por su sacrificio en la cruz. Pero es quizás para Francisco el momento de la encarnación el que tiene especial relevancia para él, ya que nada puede sustraerse del alcance de la encarnación sin que al mismo tiempo se parcialice la obra redentora de Cristo. Osuna se refiere en esta línea a María diciendo: «esta imperfección nunca la tuvo Cristo nuestro Redentor, ni se halló en su madre» ${ }^{80}$. De forma que considera en estrecha relación a la persona y a la obra salvífica del Hijo de Dios, a la humilde mujer de Nazaret elegida por Él sin mancha para ser la Theotokos. Como ha quedado patente, Francisco de Osuna era principalmente un místico, y de sus escritos se han intentado sustraer aquellas menciones llenas de cariño a la Virgen María, la Madre del Señor y madre nuestra.

80 Cf., FRAY FRANCISCO DE OSUNA, III Abecedario Espiritual, 14. 